\title{
Polymeric nanocomposite membranes for water treatment: a review
}

\author{
Yinghao Wen ${ }^{1} \cdot$ Jieming Yuan ${ }^{1} \cdot$ Xingmao Ma ${ }^{1} \odot$. Shiren Wang ${ }^{2} \cdot$ Yuchen Liu $^{2}$
}

Received: 3 May 2019 / Accepted: 19 May 2019 / Published online: 28 May 2019

(c) Springer Nature Switzerland AG 2019

\begin{abstract}
Water scarcity is a pressing global challenge. Filtration with actual polymeric membranes shows good capability for pollutant separation, but broad applications of polymeric membranes are limited. Filtration can be improved using nanocomposite membranes, which are formed by incorporating nanofillers into polymeric membrane matrixes. The most extensively investigated nanofillers are carbon-based nanoparticles and metal/metal oxide nanoparticles. Here, we review the performance of nanocomposite membranes in antifouling and permeability, their physical and chemical properties and we compare nanocomposite membranes with bare membranes. Nanocomposite membranes generally display better antifouling properties due to the antimicrobial properties of nanoparticles and the reduced roughness of membrane. They also demonstrate higher permeability because of the higher porosity and narrower pore size distribution created by nanofillers. The concentration of nanofillers changes membrane performance, and the optimal concentration depends on both the properties of nanoparticles and the membrane composition. Higher concentrations of nanofillers above the optimal value result in poor performance due to nanoparticle aggregation. Despite intensive research in the synthesis of nanocomposite membranes, most previous efforts are limited to laboratory scale, and the long-term membrane stability following nanofiller leakage has not been extensively investigated.
\end{abstract}

Keywords Nanocomposite membrane $\cdot$ Nanofiller $\cdot$ Antifouling $\cdot$ Permeability

\section{Introduction}

Rapidly growing world population exert unprecedented pressure on the clean water supply. The World Health Organization predicted that half of the world's population will live in water-stressed areas by 2025 (WHO 2018). Protecting existing fresh water sources and developing technologies to augment current water supplies are imperative (Pendergast and Hoek 2011).

Membrane filtration is deemed as the most viable technology to address current water challenges because it requires minimal chemical or thermal input and does not produce harmful by-products (Shannon et al. 2010). More importantly, membrane filtration is capable of selectively

Xingmao Ma

xma@civil.tamu.edu

1 Zachry Department of Civil and Environmental Engineering, Texas A\&M University, TAMU 3136, College Station, TX 77843-3136, USA

2 Department of Industry and Systems Engineering, Texas A\&M University, College Station 77843-3131, USA removing contaminants by modifying membrane structures and pore sizes (Qadir et al. 2017; Yin and Deng 2015). A common driving force for membrane separation is pressure (Van der Bruggen et al. 2003). Pressure-driven membranes can be categorized as microfiltration, ultrafiltration, nanofiltration, reverse osmosis, and forward osmosis based on the membrane pore sizes and operating mechanisms. Microfiltration is typically used to remove suspended solids, prokaryotes, yeasts, and fungi, while ultrafiltration is often used to remove virus, colloids, and macromolecules. Nanofiltration mainly targets hardness, heavy metals, and dissolved organic matters, and reverse osmosis is used for desalination, water reuse, and ultrapure water production (Bernardo et al. 2009; Pendergast and Hoek 2011; Ulbricht 2006).

Based on the composition, membranes are divided into polymeric membranes and inorganic membranes. Both types of membranes have been extensively explored for water filtration. Inorganic membranes are highly resistant and durable to corrosive chemicals such as strong acids, bases, and oxidants and have good mechanical strength and temperature tolerance. Inorganic membranes are also superior to polymeric membranes in maintenance because they are 
less vulnerable to bacterial degradation. Chemical cleaning at high temperature can be used to eliminate biofouling and achieve high flux recovery (Amin et al. 2016). In many applications that require harsh environmental conditions, inorganic membranes are the only option. However, due to the high manufacturing cost, difficulties in handling, and relatively poor control in pore size distribution, inorganic membranes are less common in water treatment (Goh and Ismail 2017; $\mathrm{Ng}$ et al. 2013). In contrast, polymeric membranes have very high adaptability. Their pore sizes can be controlled into a narrow range. The membrane properties can be modified by adjusting casting conditions, monomer molecules and concentrations, additives, and coagulation bath conditions (Goh and Ismail 2017). However, polymeric membranes also have several critical drawbacks. A main disadvantage is their susceptibility to fouling due to their inherent hydrophobicity (Lee et al. 2016a, b, c). They also have low resistance to chlorine. Depending on the extent of fouling, intensive physical and chemical washing might be required, or the membrane replaced ( $\mathrm{Ng}$ et al. 2013). Chlorine, as a common disinfectant in water treatment process, can react with electron-rich functional groups in polymeric membranes (Raval et al. 2010). The strong trade-off between permeability and selectivity is another challenge. It is difficult to improve one without compromising the other for the current polymeric membrane.

The limitations of current polymeric membranes prompted efforts to develop next-generation membranes with high permeability and selectivity, as well as strong antifouling and chlorine resistance properties. Advances in nanotechnology, an enabling technology at atomic level, provide a unique opportunity for membrane improvement. Engineered nanoparticles with well controlled properties at the range of $1-100 \mathrm{~nm}$ in at least two dimensions can be easily synthesized. They display unique structural, thermal, and mechanical properties compared with their bulk counterparts because the quantum size effect becomes significant at nanoscale (Kestell and DeLorey 2009). The significantly increased specific surface area is also a main reason for their unique properties (Guo et al. 2012). The initiative of incorporating nanoparticles into polymeric membrane derives from the expectation that polymeric membranes can benefit from the superior properties of nanoparticles to overcome some of their weaknesses such as their propensity for fouling. Based on the membrane structure and location of nanoparticles, different types of nanocomposite membranes can be manufactured including conventional mix-matrix nanocomposite, thin-film nanocomposite, thin-film composite with nanocomposite substrate, and surface located nanocomposite (Qadir et al. 2017; Yin and Deng 2015), as shown in Fig. 1. This review aims to provide a comprehensive survey of nanocomposite membrane development, discussing not only the antifouling property and permeability, but also the enhanced mechanical and chemical properties of nanocomposite membranes. At the end of the review, several key challenges in nanocomposite membrane development will be discussed and future needs in research highlighted.
Fig. 1 Five types of nanocomposite membranes: a Conventional nanocomposite; b surface-coated membrane; c thin-film composite (TFC) with nanocomposite substrate; d thin-film nanocomposite, and $\mathbf{e}$ surface-coated thin-film composite. ENP: engineered nanoparticles (a) Conventional nanocomposite

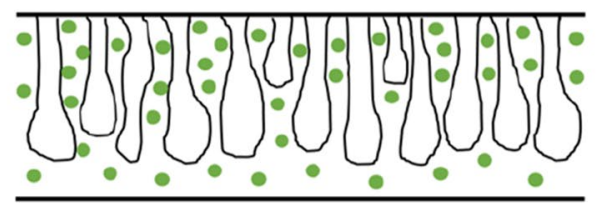

(c) TFC with nanocomposite substrate

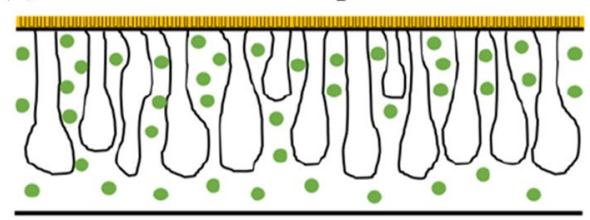

(b) Surface coated membrane

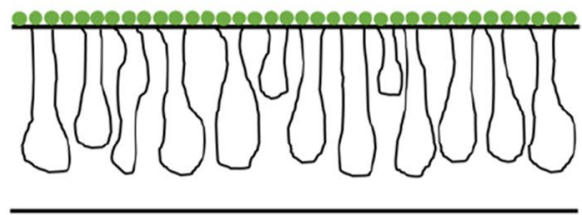

(d) Thin film nanocomposite

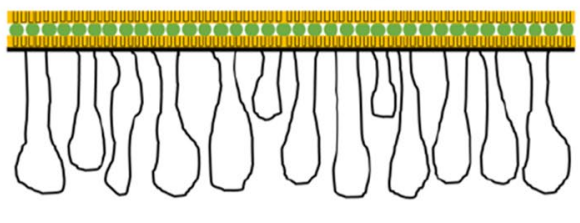

(e) Surface coated TFC

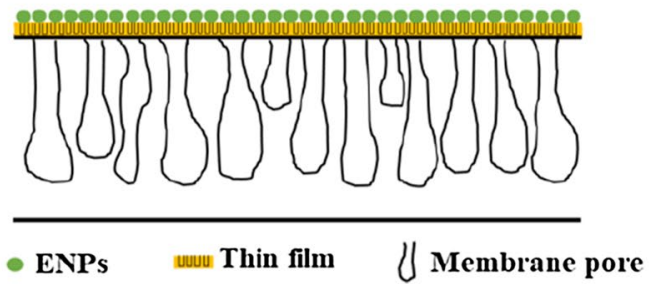




\section{Membrane fouling}

Membrane fouling is caused by the attachment of foulants on membrane surface or into internal membrane structure. Based on the characteristics of foulants, fouling is categorized into crystalline fouling (e.g., mineral precipitates), organic fouling (e.g., oils, polyelectrolytes, humics), colloidal fouling (e.g., clay, flocs), and biofouling (e.g., bacteria, fungi) (Flemming 1997), as shown in Fig. 2. Biofouling is the most concerned type of membrane fouling. Electrostatic and hydrophobic interactions between surface and microorganisms dictate the attachment efficiency. In general, attachment is more favorable for more hydrophobic, non-polar, and rough surfaces, making pristine polymeric membrane vulnerable for biofouling.

\section{Carbon nanotubes}

To minimize fouling, different types of nanoparticles have been incorporated into polymeric membrane matrix to lower membrane hydrophobicity, reduce membrane roughness, and modify surface properties. Carbon nanotubes and graphene oxide can induce reactive oxygen species upon direct contact with microorganisms and are antimicrobial (Kang et al. 2008). However, the high hydrophobicity of pristine carbon nanotubes makes them less ideal as a membrane nanofiller. Significant efforts have been made to functionalize their surfaces to enhance their hydrophilicity (Lee et al. 2016a, b, c). Acid treatment using a mixture of concentrated sulfuric acid $\left(\mathrm{H}_{2} \mathrm{SO}_{4}\right)$ and nitric acid $\left(\mathrm{HNO}_{3}\right)$ increases its hydrophilicity by providing oxygencontaining functional groups. In addition, oxygen-rich groups tend to deprotonate at circumneutral $\mathrm{pH}$, making functionalized carbon nanotubes negatively charged and more hydrophilic. A polyamide/polysulfone thin-film nanocomposite reverse osmosis membrane impregnated with $0.2 \%(\mathrm{~m} / \mathrm{v})$ oxidized multi-walled carbon nanotubes showed a significantly lower water contact angle than the primary membrane (Zhang et al. 2011). Similar observation was also reported by other researchers (Celik et al. 2011a, b). Cross-flow permeation tests with bovine serum albumin and ovalbumin showed enhanced protein fouling resistance of polyethersulfone membrane containing carbon nanotubes. As the concentration of oxygen-containing carbon nanotubes increased, the amounts of bovine serum albumin adsorbed decreased at both $\mathrm{pH} 3$ and 7 due to the increased hydrophilicity of the nanocomposite membrane and electrostatic repulsion at $\mathrm{pH}$ 7. The ability of the nanocomposite membrane to recover from protein fouling was also higher than bare polymeric membranes. The flux recovery ratio rose from $40 \%$ for the pristine membrane to a maximum of $80 \%$ for nanocomposite membrane containing $2 \%$ carbon nanotubes. However, surface roughness increased. It is likely that carbon nanotubes agglomerate on the top of each other at relatively high concentrations. Functionalization of carbon nanotube surfaces can lead to better antifouling properties and lower roughness. Functional groups successfully applied in this purpose include carboxyl functional group, polyethylene glycol groups, and amine group (Bai et al. 2015; Rahimpour et al. 2012). The total fouling resistance of nanocomposite membrane containing amine-functionalized carbon nanotubes decreased by $20.2 \%$, compared with bare polyethersulfone membranes. Other functional groups leading to varying degrees of improvement in antifouling properties of nanocomposite membranes include 5-isocyanato-isophthaloyl chloride (Qiu et al. 2009), hyperbranched poly amine-ester (Zhao et al. 2012), aluminosilicate (Baroña et al. 2013), and hydroxyl functional group (Majeed et al. 2012).

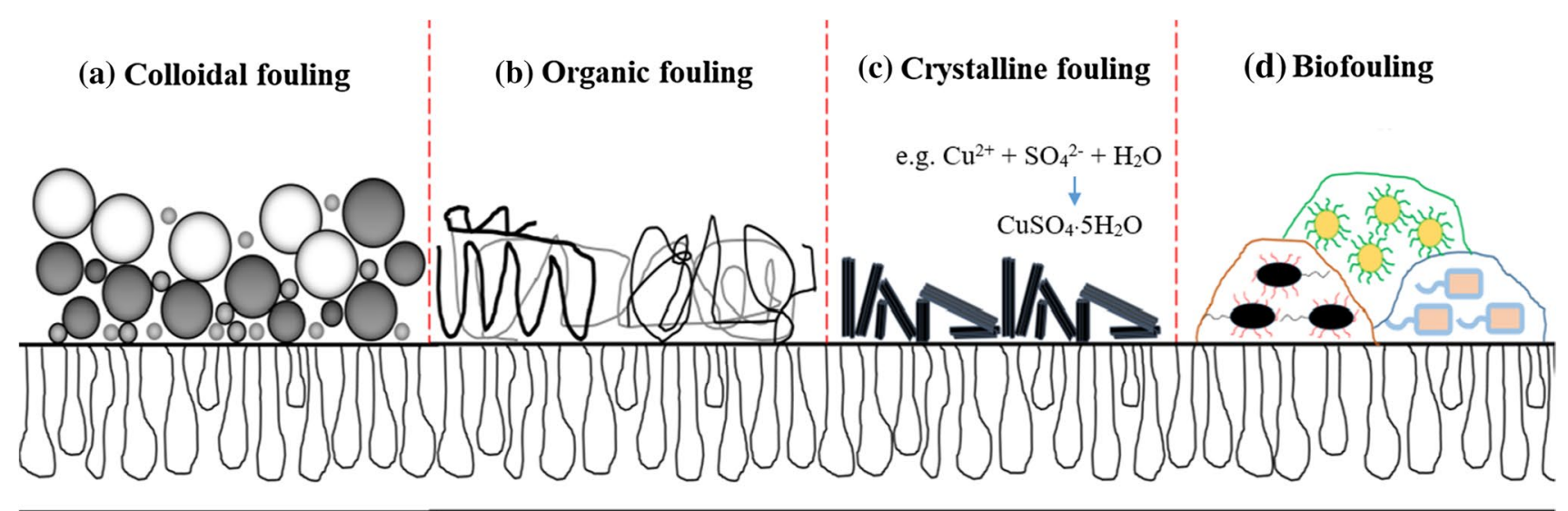

Fig. 2 Four types of fouling mechanisms: a Colloidal fouling, $\mathbf{b}$ organic fouling, $\mathbf{c}$ crystalline fouling, $\mathbf{d}$ biofouling 


\section{Graphene oxide}

Graphene oxide refers to the graphene layer intercalated with different oxygen-rich functional groups such as carboxyl, hydroxyl, and epoxy groups (Kang and Cao 2012). Hu et al. (2010) reported that graphene oxide and reduced graphene oxide nanosheets inhibited metabolic activities of $E$. coli by $\sim 80 \%$ and $\sim 70 \%$, respectively, compared to the control group. The sharp edges of graphene oxide are deemed as the main reason for the punctured cell membranes (Zhao et al. 2013). Aggregated graphene nanosheets could also wrap individual $E$. coli cells and isolate them from its ambient microbial environment (Krishnamoorthy et al. 2012). Graphene oxide-incorporated polyamide membrane effectively inhibited E. coli growth (Perreault et al. 2013). The colonyforming units (CFU) of $E$. coli declined by $64.5 \%$ after 1 -h contact with graphene oxide polyamide nanocomposite membrane.

Different functionalization approaches were explored to further improve the graphene oxide nanocomposite membranes performance. Hyperbranched polyethylenimine was grafted on graphene oxide before they were embedded into polyethersulfone membrane, which enhanced the compatibility between graphene oxide and polymeric macromolecules and reduced water contact angle from $85.5^{\circ}$ (raw membrane) to 63.1 (Yu et al. 2013). Choi et al. (2013) reported a layer-by-layer assembly of alternating positively charged amine-containing graphene oxide and negatively charged graphene oxide nanosheets on polyamide/polyethersulfone membranes. In addition to the electrostatic force that closely bound alternating nanomaterials, hydrogen bonding between uncharged functional groups such as amide, carboxylic acid, and hydroxyl groups also contributed to the stability of the nanocomposite membrane. The measured average roughness with 10 alternative layers of graphene oxide was $53.8 \%$ smaller than uncoated membrane (Choi et al. 2013).

Recently, carbon nanotube/graphene oxide complex has been proposed as a solution to overcome drawbacks of single nanomaterials such as poor dispersion of carbon nanotubes in polymeric membranes (Lee et al. 2016a, b, c). Graphene oxide can function as a surfactant to facilitate the dispersion of carbon nanotubes in aqueous solutions via noncovalent interactions (Akhavan et al. 2011; Qiu et al. 2010). A nanocomposite membrane with a ratio of 5:5 (graphene oxide/carbon nanotube) exhibited superior antifouling performance compared to membranes containing only one of them (Zhang et al. 2013).

\section{Metallic nanoparticles}

Antimicrobial metal-based particles are also widely incorporated into polymeric membranes (Mauter et al. 2011). These metal-based nanoparticles can reduce the adsorption or attachment of foulants on the membrane surface or inner structure (Zhang et al. 2016) or actively destruct cell structures to eliminate proliferative fouling. Silver nanoparticlesincorporated polysulfone membrane displayed enhanced hydrophilicity and decreased roughness as indicated by a $20 \%$ reduction of the water contact angle at $1 \mathrm{wt} \%$ compared to the bare membrane (Koseoglu-Imer et al. 2013). Polyethylene nanocomposite membrane with titanium oxide nanoparticles also exhibited greater antifouling performance than bare membranes. In particular, the hydrophilicity of titanium oxide-containing nanocomposite membrane increases under UV radiation because that the UV radiation creates surface oxygen vacancies at bridging site, which makes the surface more favorable for dissociative water adsorption (Wang et al. 1997). $100 \%$ sterilization was achieved for a titanium oxide polyamide nanocomposite membrane under UV illumination, while only $63 \%$ reduction was achieved for the same membrane without UV illumination (initial concentration at $6 \times 10^{4}$ $\mathrm{CFU} / \mathrm{ml}$ ) (Kim et al. 2003). Zinc oxide nanoparticles share a similar photocatalytic antimicrobial mechanism as titanium oxide nanoparticles, but are more stable and less expensive. Zinc oxide nanoparticles can absorb light with the wavelength from 350 to $470 \mathrm{~nm}$, while titanium oxide can only absorb light from 400 to $420 \mathrm{~nm}$ (Sakthivel et al. 2003). The selfcleaning efficiency of polyvinylidene fluoride membrane with zinc oxide nanoparticles increased from 62 to $93 \%$ as the nanoparticle content increased from 0 to $1.5 \mathrm{wt} \%$ (Hong and He 2014). The enhanced hydrophilicity under UV illumination plays an essential role in the improved self-cleaning/antifouling property. Varying the ratio of zinc oxide in the nanocomposite membrane from 0.5 and 1.5 to $3.0 \mathrm{wt} \%$ increased the decolonization efficiency from 55 to $77 \%$ and $86 \%$. The enhanced decolonization activity was primarily attributed to the production of reactive oxygen species induced by zinc oxide nanoparticles (Laohaprapanon et al. 2017). Detailed mechanisms for improved antifouling performance of nanocomposite membranes are illustrated in Fig. 3.

In addition to nanoparticle composition and concentration, physiochemical properties of metallic nanoparticle such as their shape and surface properties are important factors affecting the nanocomposite membrane performance, with the nanoparticle shape being a primary factor. For instance, zinc oxide nanorod in polyethersulfone membrane resulted in a smaller water contact angle than the spherical zinc oxide nanoparticles due to the higher migration of zinc oxide nanorods toward the membrane surface (Rajabi et al. 2015).

\section{Permeability and selectivity}

Permeability of a membrane refers to its ability to pass flow, and a high permeability requires the membrane to be highly porous, ultrathin, and has low channel tortuosity. Selectivity 
(a) Hydrophilicity

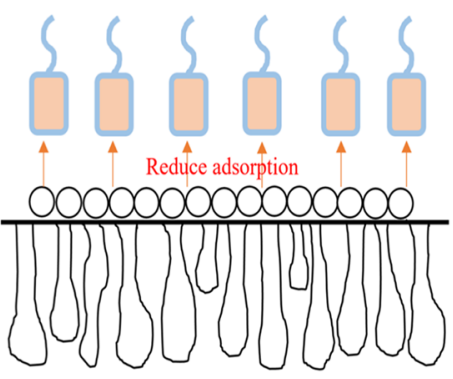

\section{(c) Generation of ROS groups}

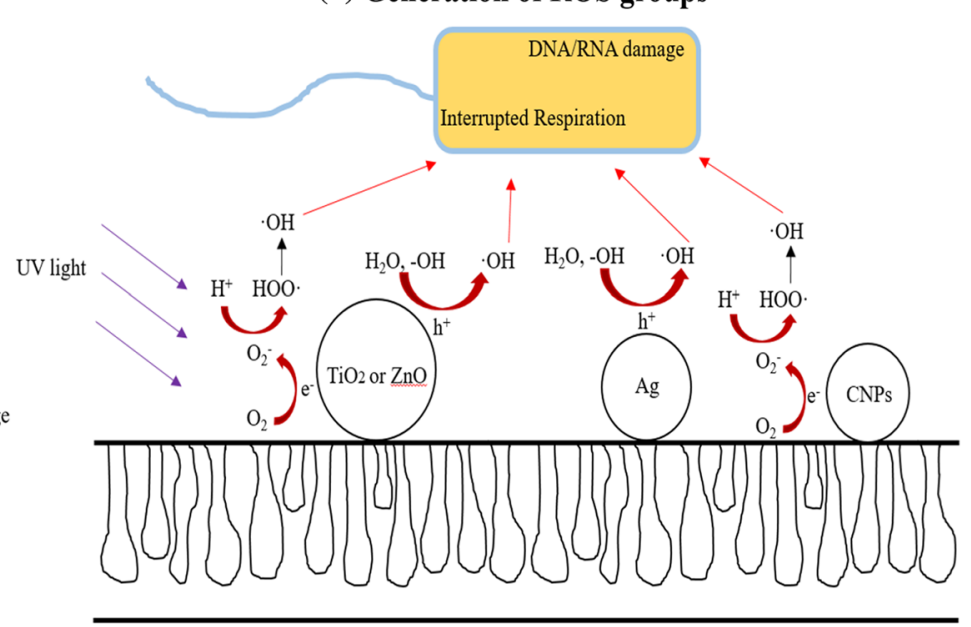

(b) Direct contact

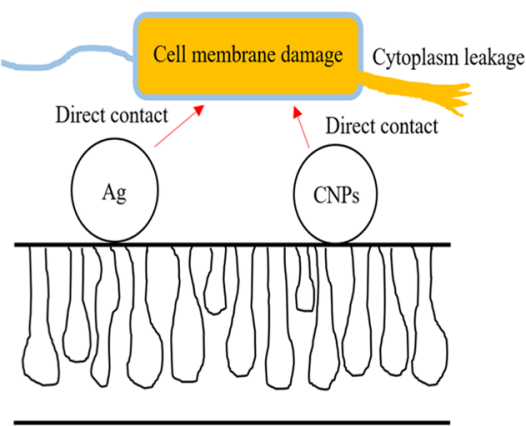

reactive oxygen species (ROS) production leads to in vitro apoptosis. $\mathrm{Ag}$ : silver nanoparticles; CNPs: carbon-based nanoparticles; $\mathrm{TiO}_{2}$ :

Fig. 3 Three antifouling mechanisms: a increasing hydrophilicity of membrane surface to minimize hydrophobic interaction, b piercing membranes of microorganisms causing cytoplasm leakage, and $\mathbf{c}$ titanium oxide; $\mathrm{ZnO}$ : zinc oxide

of a membrane refers to its capability to separate target molecules from the rest of the fluid, and a high selectivity requires small and uniform pores and appropriate surface chemistry (Bazhin 2015). Almost, all membranes have a trade-off relationship between permeability and selectivity except for biological membranes, which are both highly permeable and selective due to its unique structure and cell regulation. Based on the understanding of biological and synthetic membranes, key membrane features helpful to overcome the trade-off include properly sized pores, narrow pore size distribution, a thin active layer, and highly tuned interaction between target compounds and the membrane (Zhang et al. 2010).

Natural organic matter is composed of a heterogeneous mixture of humic substances, hydrophilic acids, proteins, lipids, carbohydrates, and hydrocarbons and is a main target of membrane filtration. Microfiltration and ultrafiltration membranes only reject $20-50 \%$ of natural organic matters with mean size smaller than $1 \mathrm{~nm}$. Nanofiltration and reverse osmosis membranes, however, can block over $90 \%$ of organic matters by size exclusion. Salt ion rejection depends on the hydration energy of individual ions. The higher the solute hydration, the higher the solute rejection. Highervalence ions typically have higher rejection rate due to the stronger electrostatic repulsion from charged membranes (Garba et al. 2003; Murthy and Gaikwad 2013). To minimize the trade-off relationship, selectivity of low-pressure membranes and permeability of high-pressure membranes need to be improved.

\section{Carbon-based nanoparticles}

Hinds et al. (2004) reported that fluid flow rates were boosted four to five orders of magnitude by incorporating aligned multi-walled carbon nanotubes in a polystyrene membrane (Yang et al. 2016). Similarly, the permeability of nanocomposite polycarbonate membrane with carbon nanotubes was several orders of magnitude higher, despite having pore sizes about one order of magnitude smaller (Hinds et al. 2004). Later analyses revealed that well-aligned carbon nanotubes work as highly efficient pores because that the unique hollow structure enables frictionless transport of water molecules through the channels (Das et al. 2014; Elimelech and Phillip 2011; Holt et al. 2006). Theoretically, the strong hydrophobic interactions of carbon nanotubes with natural organic matters enable the carbon nanotube nanocomposite membranes to achieve better rejection of natural organic matters or hydrophobic organic compounds 
(Lee et al. 2016a, b, c). For inorganic ions, a range of interactions including size exclusion, steric hindrance, and electrostatic interaction contribute to their rejection by carbon nanotubes. Bulky hydrated salt ions can be excluded by the innermost tubes and interstitial voids between graphene sheets of carbon nanotubes (Qiu et al. 2009). They are also impeded by functional groups on carbon nanotubes via steric effects. Depending on functional groups, ions with the same charges are repelled, and those with opposite charges are attracted. Electro-neutrality prevents random migrating of ions, and thus, both cations and anions are retained (Corry 2008; Fornasiero et al. 2008).

Indeed, many recent studies reported improvements in the trade-off relationship between permeability and selectivity by incorporating carbon nanotubes in membranes. For example, the permeation fluxes of sodium chloride and purified terephthalic acid solutions increased as the concentration of functionalized carbon nanotubes increased in a polyamide/ polyethersulfone membrane, reaching a maximum of 71 and $41 \mathrm{~L} / \mathrm{m}^{2} \mathrm{~h}$, respectively (Zhang et al. 2011). In addition to the hollow channels formed by aligned nanotubes, aggregation of nanotubes might form intact networks interconnected with original pores in the membrane which further increased flux as the concentration of carbon nanotubes increased. The optimized cross-linking density, polarity, and polymer structure of the nanocomposite membrane are key factors for the higher permeability and selectivity of nanocomposite membranes (Kim et al. 2014). Proper functionalization of carbon nanotubes can often lead to better performance. The pure water flux of polyaniline/polyethersulfone membrane with $2 \%$ hydroxyl-functionalized carbon nanotubes was increased to a maximum of $1498.1 \mathrm{~L} / \mathrm{m}^{2} \mathrm{~h}$ from $20.4 \mathrm{~L} / \mathrm{m}^{2} \mathrm{~h}$ under 0.1 MPa (Lee et al. 2016a, b, c). The dramatic increase in water permeability was ascribed to the synergetic effects of membrane porosity and hydrophilicity.

Graphene oxide nanocomposite membranes also displayed high permeability; however, the mechanisms for enhanced permeability by GO nanosheets are not fully understood. Potential mechanisms include: (1) water molecules can pass through graphene oxide in a low-friction flow between hydrophobic channels (Nair et al. 2012); and (2) defects on graphene oxide nanosheets may function as aggregation points for water molecules, and the hydrophilic edges work as "gates" for accumulated water molecules to slip through. After passing the "gates," water molecules enter the hydrophobic 2D channels between graphene oxide nanosheets and accelerate to a high speed due to low friction (also known as drag-reducing effect). The larger lateral size of graphene oxide nanosheets can prolong 2D hydrophobic channels and thus result in higher water speed at the end of channels (Wang et al. 2016).

A polyvinylidene fluoride nanocomposite membrane containing 1\% 3-aminopropyltriethoxysilane-functionalized graphene oxide achieved a maximum pure water flux of $401 \mathrm{~L} / \mathrm{m}^{2} \mathrm{~h}$ under $0.1 \mathrm{MPa}, 11.1 \%$ and $70.8 \%$ higher than that of unfunctionalized graphene oxide nanocomposite membrane and bare membrane, respectively. Similar result was achieved by a nanocomposite polyethersulfone membrane with O-(carboxymethyl)-chitosan-modified graphene oxide. Graphene oxide nanocomposite membranes also enhanced retention of organic contaminants. Addition of $0.1 \mathrm{~g} / \mathrm{L}$ polyethyleneimine-functionalized graphene oxide in polyelectrolyte membrane resulted in the formation of a polymer-polymer hybrid membrane, leading to $99.5 \%$, $99.3 \%$, and $87.6 \%$ rejection for Congo red, Methyl blue, and Methyl orange, respectively. The results could be explained by Donnan repulsion between membrane surface and anionic dye molecules. Furthermore, rejection for $\mathrm{MgSO}_{4}$ and $\mathrm{NaCl}$ was increased by $10.4 \%$ and $21.7 \%$, respectively (Wang et al. 2012a, b).

\section{Metallic nanoparticles}

Polyvinyl chloride-blended cellulose acetate membranes with $0.01,0.1$, and $1 \mathrm{wt} \%$ hematite $\left(\mathrm{Fe}_{3} \mathrm{O}_{4}\right)$ nanoparticles showed higher porosity and increased channels with increasing $\mathrm{Fe}_{3} \mathrm{O}_{4}$ content. However, the maximum water flux was achieved at $0.1 \mathrm{wt} \%$. Further, increase of $\mathrm{Fe}_{3} \mathrm{O}_{4}$ to $1 \mathrm{wt} \%$ reduced water flux due to channel blockage (Gholami et al. 2014). $\mathrm{Fe}_{3} \mathrm{O}_{4}$ is an effective adsorbent for heavy metals; therefore, the salt rejection of $\mathrm{Fe}_{3} \mathrm{O}_{4}$ nanocomposite membrane was significantly improved to $46 \%$ at $0.1 \mathrm{wt} \%, 228.6 \%$ higher than the bare membrane. When $\mathrm{Fe}_{3} \mathrm{O}_{4}$ content was increased to $1 \mathrm{wt} \%$; however, the salt rejection was $52 \%$ lower than $0.1 \mathrm{wt} \%$ nanocomposite membrane (Gholami et al., 2014). The reduced effective surface area due to accumulation and agglomeration of nanoparticles was considered a primary reason for lower salt rejection at higher nanoparticle content. Similar phenomenon that an optimal content of metal particles exist for maximum permeability and salt rejection was also reported for other metallic nanoparticles such as zero-valent iron nanoparticles, zinc oxide nanoparticles, and titanium oxide nanoparticles (Daraei et al. 2012; Zhang et al. 2012).

The optimal content of metallic nanoparticles in membranes depends on both the properties of polymeric membranes and nanoparticles. For example, the addition of $0.5 \mathrm{wt} \% 70 \mathrm{~nm}$ silver nanoparticles in a polysulfone membrane resulted in a lower water flux $(-20 \%)$, while addition of $0.5 \mathrm{wt} \% 30 \mathrm{~nm}$ silver nanoparticles led to a $186.7 \%$ increase in water flux (Mollahosseini et al. 2012). The relatively poorer performance of larger silver nanoparticles was likely due to pore blockage. Smaller nanoparticles also resulted in a smoother membrane surface and smaller pore size (Mollahosseini et al., 2012). For photoactive nanoparticles, UV radiation often leads to better performance. 
The molecular weight cutoff (MWCO) of UV-irradiated zinc oxide nanoparticle polyethersulfone nanocomposite membrane was $5275 \mathrm{Da}, 13.7 \%$ higher than the same nanocomposite membrane without UV radiation (Kusworo et al. 2018). Among all metal oxide nanoparticles, zirconium oxide nanoparticles are chemically more stable, and therefore more suitable for membrane filtration under harsh conditions. Polyethersulfone nanocomposite membrane with zirconium oxide nanoparticles had 20 times higher water permeability than bare polyethersulfone membrane (Maximous et al. 2010).

\section{Physical properties}

While fouling and membrane permeability and selectivity are key parameters of membrane performance, these parameters are heavily affected by the physical properties of membrane, which are also modified by nanofillers in membrane (Lee et al. 2016a, b, c). These physical parameters include the mean membrane pore size, porosity, and mechanical strength. Two parameters are currently used to indicate the mechanical strength of membranes including Young's modulus and the tensile strength.

\section{Carbon-based nanomaterials}

At lower concentrations, the hydrophobicity of carbon nanotubes enhanced the exchange of solvent and non-solvent during phase inversion and enabled carbon nanotubes to collocate regularly in the matrix. However, the mean pore size began to decrease when the concentration of carbon nanotube additive increased because steric hindrance and electrostatic interactions between carbon nanotubes and polymer matrix became significant (Qiu et al. 2009). The narrowest pore size distribution was achieved at $0.5 \mathrm{wt} \%$ carbon nanotubes. These changes corroborate with the studies on membrane fouling and permeability that an optimal concentration of carbon nanotubes exists to yield the greatest antifouling property and permeability. Functionalization of carbon nanotubes generally leads to similar results as pristine carbon nanotubes in terms of the membrane pore size. However, the mean pore size of hydroxyl-functionalized carbon nanotubes/polyethersulfone nanocomposite membrane was almost unchanged as the concentration of carbon nanotubes increased from 0 to $2 \%$, and the porosity decreased as the concentration of additive increased. The results might be due to the higher viscosity of membrane solution after nanotube addition, which slowed down the exchange of solvent and non-solvent during fabrication. The increase in solution viscosity suggested the formation of stronger network between hydroxyl-carbon nanotubes and polymer matrix and better dispersion (Lee et al. 2016a, b, c). The tensile strength of the nanocomposite membrane reached a maximum value of $15 \mathrm{MPa}$ at $2.0 \mathrm{wt} \%$ hydroxyl-carbon nanotubes, which almost doubled that of raw membrane (Majeed et al. 2012).

Remarkable improvements in mean pore size and porosity have also been reported for graphene oxide nanocomposite membranes. The mean pore size of a graphene oxide/ polyimide hybrid membrane increased from 0.71 to $0.98 \mathrm{~nm}$ with $3.5 \mathrm{wt} \%$ graphene oxide (Zaman et al. 2018). Graphene oxide nanocomposite membranes also exhibit excellent mechanical strength. The tensile strength and Young's modulus for a nanocomposite membrane were $27.3 \%$ and $22.0 \%$ higher than those of bare membrane. When the concentration exceeded $3 \%$, crystallinity of graphene oxide in membrane was compromised by its irregular collocation and aggregation (Yu et al. 2013). The large specific surface area and good dispersion of graphene oxide at an optimum concentration could increase the load-bearing capacity of membranes (Lee et al. 2015). The improvement in tensile strength was ascribed to the excellent mechanical properties of graphene oxide (Wang et al. 2012a, b). In fact, graphene oxide is one of the strongest materials known, with a Young's module of $0.2-0.25 \mathrm{TPa}$ (Lee et al. 2008). Modifications of graphene oxide and polymer interactions through hyperbranching and covalent bonding between graphene oxide additives and polymer matrix are likely to further improve the physical properties of nanocomposite membranes (Wang et al. 2012a, b; Xu et al. 2014; Yu et al. 2013; Zhao et al. 2012).

\section{Metallic nanoparticles}

The higher hydrophilicity of metallic nanoparticles can accelerate the exchange of solvent and non-solvent in casting solution, leading to a more porous membrane structure (Mulder 2012). The mean pore size of zinc oxide/polyvinylidene fluoride membrane increased from $28.1 \mathrm{~nm}$ for the bare membrane to $33.6 \mathrm{~nm}$ for the nanocomposite membrane with $6.7 \mathrm{wt} \%$ zinc oxide, and the pore density (number of pores per unit area) increased from 44.1 to $49.8 \mu \mathrm{m}^{2}$ (Liang et al. 2012). A dramatic increase of $180 \%$ of macro-void mean size was observed when $1 \mathrm{wt} \%$ hematite was embedded into polyethersulfone membrane.

Metallic nanoparticles can also serve as a cross-linking agent and result in an increase in membrane rigidity (Ogoshi and Chujo 2005). $0.1 \mathrm{wt} \%$ zinc oxide/polyethersulfone nanocomposite membrane was reported to have $2.1 \mathrm{Mpa}$ tensile strength, $90.9 \%$ higher than bare membrane, and the membrane elongation at break also increased from 1.15 to $2.2 \%$ (Hong and He 2014). Other nanoparticles such as aluminum oxide and titanium oxide nanoparticles could also lead to stronger and more porous membranes. The optimal concentration required for metallic nanoparticles is generally higher than carbon-based nanoparticles. 


\section{Chlorine resistance}

Chlorine is one of the most broadly used disinfectants in drinking water treatment. Chlorine and hypochlorite ions are also used for taste and odor control. In a membrane system, chlorine can be an effective biocide. Unfortunately, the amide group and aromatic ring in polymeric membranes are very susceptible to chlorine oxidation. Since amide is an electron-donating group, it can donate an electron to chlorine atom, forming $\mathrm{N}-\mathrm{Cl}$ bond (N-chlorination). Aromatic ring is also electron-rich and vulnerable for chlorine attack (ring chlorination) (Raval et al. 2010). Subsequent amide bond cleavage via hydrolysis could destroy intermolecular hydrogen bonds and eventually the polyamide network (Choi et al. 2013).

Dramatic enhancement in chlorine resistance was observed in an amide-graphene oxide-incorporated polyamide membrane. After being exposed to $6000 \mathrm{mg} / \mathrm{L}$ of chlorine solution for $1 \mathrm{~h}$, the normalized $\mathrm{NaCl}$ rejection rate of the composite membrane maintained as high as $92.3 \%$, compared to $\sim 51 \%$ for the pristine membrane. Although longer exposure eventually destroyed both membrane structures to the same degree, membrane containing amide-graphene oxide exhibited remarkably slower decline in normalized $\mathrm{NaCl}$ rejection. Such phenomenon was likely related to the densely cross-linked inner core layer sandwiched by two looser outer layers. Salt rejection is mainly determined by the inner layer. Upon contact with chlorine, the inner layer remains largely unaffected until the outer layer has been damaged, which explains the slower decline in salt rejection. In addition, graphene oxide layer could function as a barrier that protects underlying polyamide layers from chlorine attack. Although the mechanisms for chlorine resistance are yet to be fully understood, size exclusion by graphene oxide layer was believed to be one of them, since reactive chlorine species (e.g., $\mathrm{OCl}^{-}$) is larger than the $\mathrm{Cl}^{-}$and its passage is restricted (Choi et al. 2013). The electron-rich graphene oxide could also shield susceptible sites in polyamide matrix from chlorine oxidation (Song et al. 2016). Active chlorine could form $\mathrm{O}-\mathrm{Cl}$ bonds with electron-donating groups in graphene oxide instead of forming $\mathrm{N}-\mathrm{Cl}$ bonds with amide groups in polyamide matrix (Shao et al. 2017). Furthermore, charge exclusion between negatively charged graphene oxide and $\mathrm{OCl}^{-}$species could be important in impeding diffusion of chlorine species. Similar results were also reported for other graphene oxide/polyamide membranes (Chae et al. 2015; Hu et al. 2017a, b). However, most graphene oxide composite membranes with enhanced chlorine resistance are polyamide membranes; it is unknown whether other membranes will also benefit from the enhanced chlorine resistance by graphene oxide.
Reports of other carbon-based and metal-based nanoparticles in other polymeric membranes for improved chlorine resistance are limited. A recent study showed that polyamide membranes mixed with functionalized carbon nanotubes also exhibited enhanced chlorine resistance, likely due to that electron-rich carboxylate groups on carbon nanotubes protect the amide functional group from chlorine attack (Zhao et al. 2014). Future studies are needed to unveil mechanisms of nanofillers on blocking chlorine attack in different polymeric membranes.

\section{Stability of nanocomposite membranes}

Although nanocomposite membranes have exhibited many remarkable properties, long-term stability of these membranes is still uncertain (Som et al. 2010). 10\% loss of silver nanoparticles was reported for a nanocomposite membrane after a relatively short filtration period, resulting in significant reduction in antifouling and antibacterial activity due to $\mathrm{Ag}^{+}$release from membrane surface (Zodrow et al. 2009). The most common pathways for nanoparticles leakage from nanocomposite membranes include direct leaching and release of trapped nanoparticles along with polymer matrix degradation. The chemistry of polymer matrix is critical in determining the stability of nanoparticles in nanocomposite membranes because the matrix anchors nanoparticles and functions as a barrier to protect them from external environment. Well-dispersed carbon nanotubes are tightly bound to polyamide membranes and show good stability (Kingston et al. 2014). Reports on carbon nanotube leaching from nanocomposite membranes are rare. Hence, it is reasonable to speculate that it is unlikely for carbon nanotubes to leach unless the polymeric membrane undergoes structural or chemical changes. Major mechanisms for membrane degradation include UV degradation, temperature extremes, mechanical stresses, and chemical erosion as illustrated in Fig. 4 (Kingston et al. 2014). The polyamide nanocomposite membrane with carbon nanotubes actually showed significantly improved stability under UV irradiation and higher temperature than raw membrane (Vilar et al. 2013). In addition, carbon nanotubes function as nucleating agents that change the lamellar orientation, dispersion, and viscosity of polyamide membrane, and thus improve the thermal and mechanical properties (Vilar et al. 2013). Therefore, chemical erosion from chlorine disinfection is likely the most possible process resulting in nanoparticle release from degraded membranes (Kingston et al. 2014).

To maintain the performance of nanocomposite membranes, various methods have been explored to immobilize nanoparticles in the membrane. One approach is the in situ generation of nanoparticles in the membrane matrix. Polydopamine deposition and in situ reduction of silver 
Fig. 4 Four mechanisms of polymer matrix degradation: UV radiation, temperature extremes, mechanical abrasion, and chemical erosion. Two ways of engineered nanoparticle (ENP) release: a release of free engineered nanoparticles due to polymer matrix degradation and b release of engineered nanoparticles along with degraded polymer matrix
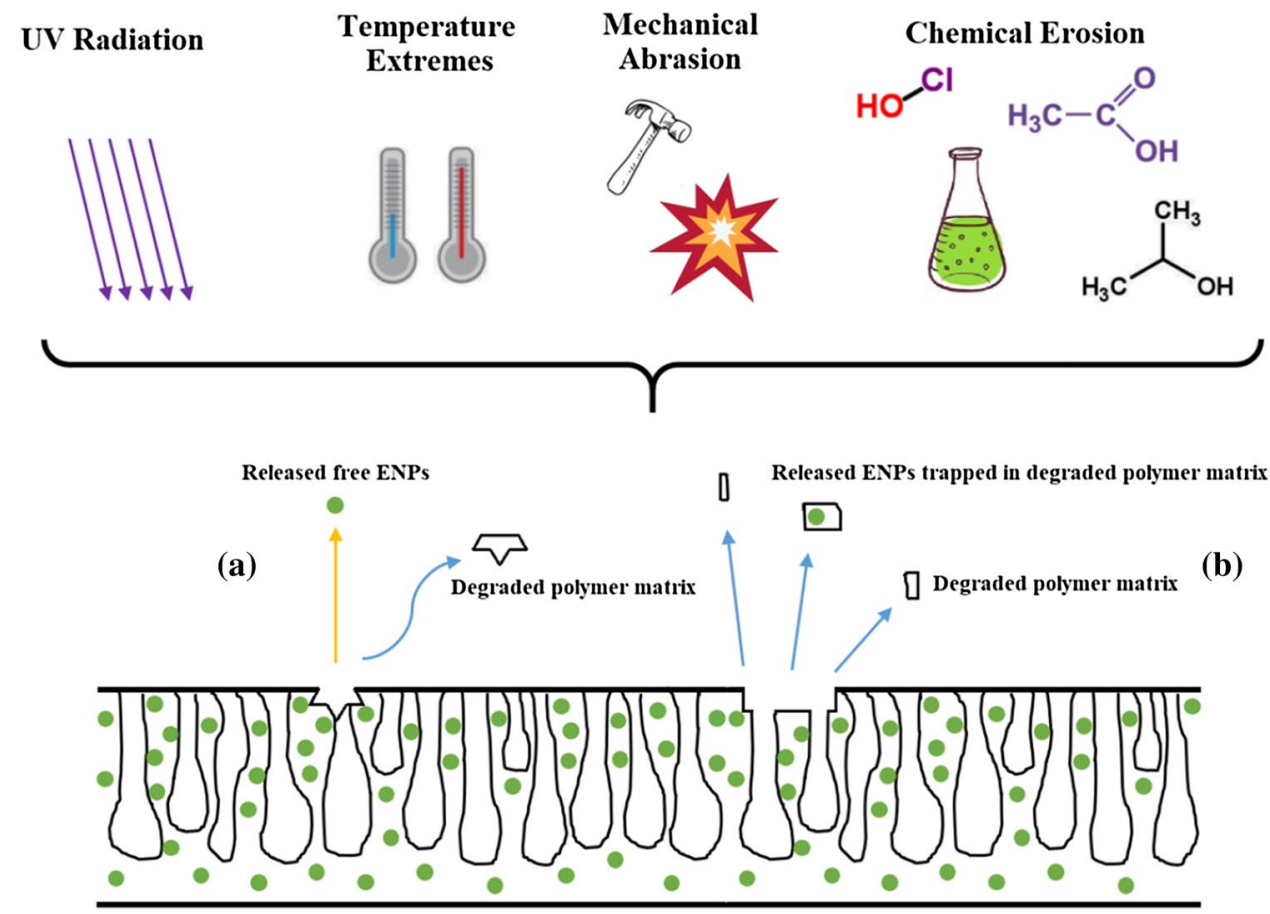

ammonia aqueous solution $\left(\mathrm{Ag}\left(\mathrm{NH}_{3}\right)_{2} \mathrm{OH}\right)$ were reported to effectively immobilize silver nanoparticles in polysulfone membrane (Som et al. 2010). Smaller particle size might mitigate nanoparticles leaching from membranes. For example, the leaching of micro-sized silver was three times higher than silver nanowire and silver nanoparticles (Hu et al. 2017a, b). The greater particle mass of microsized silver particles resulted in higher leaching of $\mathrm{Ag}$ from the composite membrane during water filtration. However, the antifouling properties of silver nanoparticles are partly due to its oxidation and release of $\mathrm{Ag}^{+}$, and more $\mathrm{Ag}^{+}$ions will be released when the size of silver nanoparticles becomes smaller. Therefore, the detachment of silver nanoparticles from nanocomposite membranes and release of $\mathrm{Ag}^{+}$need to be balanced when an optimal size range of silver is sought. Furthermore, the interaction between chemical additives and nanoparticles in the membrane also has a significant effect on nanoparticle leaching. Pluronic F127 added into a nanocomposite membrane with titanium oxide nanoparticles can effectively restrain the leaching of nanoparticles ( $\mathrm{Li}$ et al. 2014). The interaction between additives and nanoparticles can also mitigate leaching by preventing nanoparticles aggregation in membrane. A poly(vinylidene fluoride) membrane with $\mathrm{Fe} / \mathrm{Pd}$ bimetallic nanoparticles was more stable after the addition of polyacrylic acid (Wan et al. 2017). The bimetallic nanoparticles were more uniformly distributed in membrane pores at different depths with the addition of the linking molecule (Lin et al. 2009). In addition to the approaches discussed above, the combination of a relatively unstable nanoparticle with a relatively stable nanoparticle was explored as a potential approach to reduce leaching. For example, zeolites were attached to a polyamide membrane surface first via covalent binding to serve as anchors for silver nanoparticles, which could be reloaded via simple physisorption after use, and the regenerated membrane had a similar antifouling performance as the original one $(\mathrm{Wu}$ et al. 2015).

In addition to the physical stability, the chemical stability of nanoparticles also affects the stability and performance of nanocomposite membranes. In particular, graphene oxide can act as a terminal electron acceptor and be reduced to graphite by Shewanella, a group of heterotrophic and metalreducing anaerobes present in a variety of environments (Salas et al. 2010). The reduction can also occur under aerobic condition relatively fast ( $24 \mathrm{~h})$ (Wang et al. 2011). Reduction of graphene oxide by $E$. coli through glycolysis was also reported to occur within $48 \mathrm{~h}$ under anaerobic condition. Although graphene oxide is known to be antibacterial, the sheets may provide a biocompatible surface for un-inactivated E. coli to attach and proliferate (Akhavan and Ghaderi 2012).

Uniform dispersion of nanoparticles in polymeric matrix is another major challenge for producing highly performing nanocomposite membranes. Nanoparticles tend to aggregate due to strong interactions between them and weak polymer-nanoparticles interfacial interactions. Poor dispersion and aggregation of nanoparticles might result in low improvements in nanocomposite membrane performance (Liu et al. 2011). 


\section{Future research}

Despite the impressive progresses made in nanocomposite membrane synthesis, more research is needed to overcome existing challenges. First of all, understanding of nanoscale phenomena of nanoparticles in membranes is still incomplete. Efforts to incorporate two or more nanoparticles or multi-element nanostructures in the same polymer matrix may potentially enhance long-term stability and performance of membranes by compensating the shortcomings of individual ones. Metal organic frameworks (MOFs) are particularly interesting as nanofillers because they allow selective removal of certain contaminants from source water (Jabbari et al. 2016; Abdi et al. 2017; Torad et al. 2014). With the broadening of source water in desalination and new uses for filtrate, tailored membrane synthesis targeting specific water source and uses is highly preferred. Secondly, agglomeration of nanoparticles is still hindering the progress of nanocomposite membranes. Current solutions include surface modification and optimization of fabrication processes, but they only work for specific nanoparticles and polymer matrix. A common method to better disperse nanoparticles in polymer matrix may not only further enhance desired properties of nanocomposite membranes, but also make the membrane technology more feasible in industrial uses. Thirdly, the long-term stability of nanocomposite membranes requires more attention. For example, it has been reported that several carbon-based nanoparticles could protect polyamide membranes from chlorine attacks, but direct interactions between these nanoparticles and free chlorine are not well studied. Longterm effects of chlorine exposure on the alteration of functional groups on nanoparticles require more attention. In addition, studies on potential nanoparticles release from polymer membranes are very limited, and the releasing mechanisms are not fully known. Lastly, successful applications of nanocomposite membranes in the literature are mostly limited to laboratory scale. Large-scale fabrication methods and long-term tests required for industrial applications are still missing.

\section{Conclusion}

Overall, nanocomposite membranes display superior performance compared with bare membranes. The properties of nanoparticles including their size and shape, surface properties, and composition as well as the type of polymers have strong impacts on the final performance of nanocomposite membranes. For each combination of nanoparticles and polymeric membrane materials, the literature suggests that there is an optimal concentration of nanoparticles and membrane materials. Higher concentration of nanofillers does not necessarily result in better performance. Therefore, comprehensive experimental assessments are always needed for specific combinations of nanoparticles and polymeric membranes to achieve optimal outcome.

Even though publications abound, most studies on nanocomposite membranes are limited to short-term tests. The long-term stability and performance of nanocomposite membranes remain uncertain. In addition, the scale-up manufacturing of nanocomposite membrane has not been intensively investigated. Advancements in mechanistic understanding of nanoparticle polymer matrix interactions and scalable manufacturing of nanocomposite membranes will greatly enhance their applications. Future efforts should aim at developing more stable, highly performing, and scalable nanocomposite membranes for different applications.

\section{References}

Abdi J, Vossoughi M, Mahmoodi N, Alemzadeh I (2017) Synthesis of metal-organic framework hybrid nanocomposites based on GO and CNT with high adsorption capacity for dye removal. Chem Eng J 326:1145-1158. https://doi.org/10.1016/j.cej.2017.06.054

Akhavan O, Ghaderi EJC (2012) Escherichia coli bacteria reduce graphene oxide to bactericidal graphene in a self-limiting manner. Carbon 50(5):1853-1860

Akhavan O, Ghaderi E, Esfandiar A (2011) Wrapping bacteria by graphene nanosheets for isolation from environment, reactivation by sonication, and inactivation by near-infrared irradiation. J Phys Chem B 115(19):6279-6288. https://doi.org/10.1021/jp200686k

Amin S, Abdallah H, Roushdy M, El-Sherbiny S (2016) An overview of production and development of ceramic membranes. Int J Appl Eng 11(12):7708-7721

Bai L, Liang H, Crittenden J, Qu F, Ding A, Ma J, Du X, Guo S, Li G (2015) Surface modification of UF membranes with functionalized MWCNTs to control membrane fouling by NOM fractions. J Membr Sci 492:400-411. https://doi.org/10.1016/j.memsc i.2015.06.006

Baroña G, Lim J, Choi M, Jung B (2013) Interfacial polymerization of polyamide-aluminosilicate SWNT nanocomposite membranes for reverse osmosis. Desalination 325:138-147. https://doi. org/10.1016/j.desal.2013.06.026

Bazhin N (2015) Water flux in pressure retarded osmosis. Desalination 375:21-23. https://doi.org/10.1016/b978-0-12-812103-0.00002-7

Bernardo P, Drioli E, Golemme G (2009) Membrane gas separation: a review/state of the art. Ind Eng Chem 48(10):4638-4663. https:// doi.org/10.1021/ie8019032

Celik E, Liu L, Choi H (2011a) Protein fouling behavior of carbon nanotube/polyethersulfone composite membranes during water filtration. Water Res 45(16):5287-5294. https://doi.org/10.1016/j. watres.2011.07.036

Celik E, Park H, Choi H, Choi H (2011b) Carbon nanotube blended polyethersulfone membranes for fouling control in water treatment. Water Res 45(1):274-282. https://doi.org/10.1016/j.watre s.2010.07.060 
Chae H, Lee J, Lee C, Kim I, Park P (2015) Graphene oxide-embeded thin-film composite reverse osmosis membrane with highflux, anti-biofouling and chlorine resistance. J Membr Sci 483:128-135

Choi W, Choi J, Bang J, Lee J (2013) Layer-by-layer assembly of graphene oxide nanosheets on polyamide membranes for durable reverse-osmosis applications. ACS Appl Mater Interfaces 5(23):12510-12519. https://doi.org/10.1021/am403790s

Corry B (2008) Designing carbon nanotube membranes for efficient water desalination. J Phys Chem B 112(5):1427-1434. https://doi. org/10.1021/jp709845u

Daraei P, Madaeni S, Ghaemi N, Salehi E, Khadivi M, Moradian R, Astinchap B (2012) Novel polyethersulfone nanocomposite membrane prepared by PANI/ $/ \mathrm{Fe}_{3} \mathrm{O}_{4}$ nanoparticles with enhanced performance for $\mathrm{Cu}$ (II) removal from water. J Membr Sci 415:250 259. https://doi.org/10.1016/j.memsci.2012.05.007

Das R, Ali M, Hamid S, Ramakrishna S, Chowdhury Z (2014) Carbon nanotube membranes for water purification: a bright future in water desalination. Desalination 336:97-109. https://doi. org/10.1016/j.desal.2013.12.026

Elimelech M, Phillip W (2011) The future of seawater desalination: energy, technology, and the environment. Science 333(6043):712717. https://doi.org/10.1126/science. 1200488

Flemming H (1997) Reverse osmosis membrane biofouling. Exp Therm Fluid Sci 14(4):382-391. https://doi.org/10.1016/s0894 -1777(96)00140-9

Fornasiero F, Park H, Holt J, Stadermann M, Grigoropoulos NA, Bakajin O (2008) Ion exclusion by sub-2-nm carbon nanotube pores. Proc Natl Acad Sci 105(45):17250-17255. https://doi. org/10.1073/pnas.0710437105

Garba Y, Taha S, Cabon J, Dorange G (2003) Modeling of cadmium salts rejection through a nanofiltration membrane: relationships between solute concentration and transport parameters. J Membr Sci 211(1):51-58. https://doi.org/10.1016/s0376-7388(02)00328 $-9$

Gholami A, Moghadassi A, Hosseini S, Shabani S, Gholami F (2014) Preparation and characterization of polyvinyl chloride based nanocomposite nanofiltration-membrane modified by iron oxide nanoparticles for lead removal from water. J Ind Eng Chem 20(4):1517-1522. https://doi.org/10.1016/j.jiec.2013.07.041

Goh P, Ismail A (2017) A review on inorganic membranes for desalination and wastewater treatment. Desalination. https://doi. org/10.1016/j.desal.2017.07.023

Guo W, Ngo H, Li J (2012) A mini-review on membrane fouling. Biores Technol 122:27-34. https://doi.org/10.1016/j.biort ech.2012.04.089

Hinds B, Chopra N, Rantell T, Andrews R, Gavalas V, Bachas L (2004) Aligned multiwalled carbon nanotube membranes. Science 303(5654):62-65. https://doi.org/10.1126/science.1092048

Holt J, Park H, Wang Y, Stadermann M, Artyukhin A, Grigoropoulos C, Bakajin O (2006) Fast mass transport through sub-2-nanometer carbon nanotubes. Science 312(5776):1034-1037. https://doi. org/10.1126/science.1126298

Hong J, He Y (2014) Polyvinylidene fluoride ultrafiltration membrane blended with nano- $\mathrm{ZnO}$ particle for photo-catalysis self-cleaning. Desalination 332(1):67-75. https://doi.org/10.1016/j.desal .2013.10.026

Hu W, Peng C, Luo W, Lv M, Li X, Li D, Fan C (2010) Graphenebased antibacterial paper. ACS Nano 4(7):4317-4323. https://doi. org/10.1021/nn101097v

Hu M, Zhong K, Liang Y, Ehrman S, Mi B (2017a) Effects of particle morphology on the antibiofouling performance of silver embedded polysulfone membranes and rate of silver leaching. Ind Eng Chem Res 56(8):2240-2246. https://doi.org/10.1021/ acs.iecr.6b04934

Hu R, He Y, Zhang C, Zhang R, Li J, Zhu H (2017b) Graphene oxideembedded polyamide nanofiltration membranes for selective ion separation. J Mater Chem A 5(48):25632-25640. https://doi. org/10.1039/c7ta08635k

Jabbari V, Veleta J, Zarei-Chaleshtori M, Gardea-Torresdey J, Villagrán D (2016) Green synthesis of magnetic MOF@ GO and MOF@ CNT hybrid nanocomposites with high adsorption capacity towards organic pollutants. Chem Eng J 304:774-783. https:// doi.org/10.1016/j.cej.2016.06.034

Kang G, Cao Y (2012) Development of antifouling reverse osmosis membranes for water treatment: a review. Water Res 46(3):584600. https://doi.org/10.1016/j.watres.2011.11.041

Kang S, Herzberg M, Rodrigues D, Elimelech M (2008) Antibacterial effects of carbon nanotubes: size does matter! Langmuir 24(13):6409-6413. https://doi.org/10.1021/la800951v

Kestell A, DeLorey G (2009) Nanoparticles: properties, classification, characterization, and fabrication. Nova Science Publishers, New York

Kim S, Kwak S, Sohn B, Park T (2003) Design of $\mathrm{TiO}_{2}$ nanoparticle self-assembled aromatic polyamide thin-film-composite (TFC) membrane as an approach to solve biofouling problem. J Membr Sci 211(1):157-165. https://doi.org/10.1016/s0376 -7388(02)00418-0

Kim H, Choi K, Baek Y, Kim D, Shim J, Yoon J, Lee J (2014) Highperformance reverse osmosis $\mathrm{CNT} /$ polyamide nanocomposite membrane by controlled interfacial interactions. ACS Appl Mater Interfaces 6(4):2819-2829. https://doi.org/10.1021/am405398f

Kingston C, Zepp R, Andrady A, Boverhof D, Fehir R, Hawkins D, Vejins V (2014) Release characteristics of selected carbon nanotube polymer composites. Carbon 68:33-57

Koseoglu-Imer D, Kose B, Altinbas M, Koyuncu I (2013) The production of polysulfone (PS) membrane with silver nanoparticles (AgNP): physical properties, filtration performances, and biofouling resistances of membranes. J Membr Sci 428:620-628. https:// doi.org/10.1016/j.memsci.2012.10.046

Krishnamoorthy K, Umasuthan N, Mohan R, Lee J, Kim S (2012) Antibacterial activity of graphene oxide nanosheets. Sci Adv Mater 4(11):1111-1117. https://doi.org/10.1166/sam.2012.1402

Kusworo T, Soetrisnanto D, Aryanti N, Utomo D, Tambunan V, Simanjuntak N (2018) Evaluation of Integrated modified nanohybrid polyethersulfone- $\mathrm{ZnO}$ membrane with single stage and double stage system for produced water treatment into clean water. J Water Process Eng 23:239-249. https://doi.org/10.1016/j. jwpe.2018.04.002

Laohaprapanon S, Vanderlipe A, Doma B Jr, You S (2017) Self-cleaning and antifouling properties of plasma-grafted poly (vinylidene fluoride) membrane coated with $\mathrm{ZnO}$ for water treatment. J Taiwan Inst Chem Eng 70:15-22. https://doi.org/10.1016/j.jtice .2016.10.019

Lee C, Wei X, Kysar J, Hone J (2008) Measurement of the elastic properties and intrinsic strength of monolayer graphene. Science 321(5887):385-388. https://doi.org/10.1126/science.1157996

Lee J, Jang J, Chae H, Lee S, Lee C, Park P, Kim I (2015) A facile route to enhance the water flux of a thin-film composite reverse osmosis membrane: incorporating thickness-controlled graphene oxide into a highly porous support layer. J Mater Chem A 3(44):2205322060. https://doi.org/10.1039/c5ta04042f

Lee A, Elam J, Darling S (2016a) Membrane materials for water purification: design, development, and application. Environ Sci Water Res Technol 2(1):17-42. https://doi.org/10.1039/c5ew00159e

Lee J, Jeong S, Liu Z (2016b) Progress and challenges of carbon nanotube membrane in water treatment. Crit Rev Environ Sci Technol 46(11-12):999-1046. https://doi.org/10.1080/10643 389.2016.1191894

Lee J, Ye Y, Ward A, Zhou C, Chen V, Minett A, Shi J (2016c) High flux and high selectivity carbon nanotube composite membranes for natural organic matter removal. Sep Purif Technol 163:109_ 119. https://doi.org/10.1016/j.seppur.2016.02.032 
Li X, Fang X, Pang R, Li J, Sun X, Shen J, Wang L (2014) Selfassembly of TiO2 nanoparticles around the pores of PES ultrafiltration membrane for mitigating organic fouling. J Membr Sci 467:226-235. https://doi.org/10.1016/j.memsci.2014.05.036

Liang S, Xiao K, Mo Y, Huang X (2012) A novel ZnO nanoparticle blended polyvinylidene fluoride membrane for anti-irreversible fouling. J Membr Sci 394:184-192. https://doi.org/10.1016/j. memsci.2011.12.040

Lin Y, Tseng H, Wey M, Lin M (2009) Characteristics, morphology, and stabilization mechanism of PAA250K-stabilized bimetal nanoparticles. Coll Surf A 349(1-3):137-144. https://doi. org/10.1016/j.colsurfa.2009.08.007

Liu J, Gao Y, Cao D, Zhang L, Guo Z (2011) Nanoparticle dispersion and aggregation in polymer nanocomposites: insights from molecular dynamics simulation. Langmuir 27(12):7926-7933. https://doi.org/10.1021/la201073m

Majeed S, Fierro D, Buhr K, Wind J, Du B, Boschetti-de-Fierro A, Abetz V (2012) Multi-walled carbon nanotubes (MWCNTs) mixed polyacrylonitrile (PAN) ultrafiltration membranes. J Membr Sci 403:101-109. https://doi.org/10.1016/j.memsci.2012.02.029

Mauter M, Wang Y, Okemgbo K, Osuji C, Giannelis E, Elimelech M (2011) Antifouling ultrafiltration membranes via post-fabrication grafting of biocidal nanomaterials. ACS Appl Mater Interfaces 3(8):2861-2868. https://doi.org/10.1021/am200522v

Maximous N, Nakhla G, Wan W, Wong K (2010) Performance of a novel $\mathrm{ZrO} 2 / \mathrm{PES}$ membrane for wastewater filtration. J Membr Sci 352(1-2):222-230. https://doi.org/10.1016/j.memsci.2010.02.021

Mollahosseini A, Rahimpour A, Jahamshahi M, Peyravi M, Khavarpour M (2012) The effect of silver nanoparticle size on performance and antibacteriality of polysulfone ultrafiltration membrane. Desalination 306:41-50. https://doi.org/10.1016/j.desal .2012 .08 .035

Mulder J (2012) Basic principles of membrane technology. Springer, New York

Murthy ZVP, Gaikwad MS (2013) Preparation of chitosan-multiwalled carbon nanotubes blended membranes: characterization and performance in the separation of sodium and magnesium ions. Nanoscale Microscale Thermophys Eng 17:245-262

Nair R, Wu H, Jayaram P, Grigorieva I, Geim A (2012) Unimpeded permeation of water through helium-leak-tight graphene-based membranes. Science 335(6067):442-444. https://doi.org/10.1126/ science. 1211694

Ng LY, Mohammad AW, Leo CP, Hilal N (2013) Polymeric membranes incorporated with metal/metal oxide nanoparticles: a comprehensive review. Desalination 308:15-33

Ogoshi T, Chujo Y (2005) Synthesis of poly (vinylidene fluoride) $(\mathrm{PVdF}) /$ silica hybrids having interpenetrating polymer network structure by using crystallization between PVDF chains. J Polym Sci Part A Polym Chem 43(16):3543-3550. https://doi. org/10.1002/pola.20833

Pendergast M, Hoek E (2011) A review of water treatment membrane nanotechnologies. Energy Environ Sci 4(6):1946-1971. https:// doi.org/10.1039/C0EE00541J

Perreault F, Tousley M, Elimelech M (2013) Thin-film composite polyamide membranes functionalized with biocidal graphene oxide nanosheets. Environ Sci Technol Lett 1(1):71-76. https://doi. org/10.1021/ez4001356

Qadir D, Mukhtar H, Keong L (2017) Mixed matrix membranes for water purification applications. Sep Purif Rev 46(1):62-80. https ://doi.org/10.1080/15422119.2016.1196460

Qiu S, Wu L, Pan X, Zhang L, Chen H, Gao C (2009) Preparation and properties of functionalized carbon nanotube/PSF blend ultrafiltration membranes. J Membr Sci 342(1-2):165-172. https://doi. org/10.1016/j.memsci.2009.06.041

Qiu L, Yang X, Gou X, Yang W, Ma Z, Wallace G, Li D (2010) Dispersing carbon nanotubes with graphene oxide in water and synergistic effects between graphene derivatives. Chem A Eur J 16(35):10653-10658. https://doi.org/10.1002/chem.201001771

Rahimpour A, Jahanshahi M, Khalili S, Mollahosseini A, Zirepour A, Rajaeian B (2012) Novel functionalized carbon nanotubes for improving the surface properties and performance of polyethersulfone (PES) membrane. Desalination 286:99-107. https://doi. org/10.1016/j.desal.2011.10.039

Rajabi H, Ghaemi N, Madaeni S, Daraei P, Astinchap B, Zinadini S, Razavizadeh S (2015) Nano-ZnO embedded mixed matrix polyethersulfone (PES) membrane: influence of nanofiller shape on characterization and fouling resistance. Appl Surf Sci 349:66-77. https://doi.org/10.1016/j.apsusc.2015.04.214

Raval H, Trivedi J, Joshi S, Devmurari C (2010) Flux enhancement of thin film composite RO membrane by controlled chlorine treatment. Desalination 250(3):945-949. https://doi.org/10.1016/j. desal.2009.05.005

Sakthivel S, Neppolian B, Shankar M, Arabindoo B, Palanichamy M, Murugesan V (2003) Solar photocatalytic degradation of azo dye: comparison of photocatalytic efficiency of $\mathrm{ZnO}$ and $\mathrm{TiO}_{2}$. Sol Energy Mater Sol Cells 77(1):65-82. https://doi.org/10.1016/ s0927-0248(02)00255-6

Salas E, Sun Z, Lüttge A, Tour J (2010) Reduction of graphene oxide via bacterial respiration. ACS Nano 4(8):4852-4856. https://doi. org/10.1021/nn101081t

Shannon M, Bohn P, Elimelech M, Georgiadis J, Marinas B, Mayes A (2010) Science and technology for water purification in the coming decades. In: Nanoscience and technology: a collection of reviews from nature journals. World Scientific, Singapore, pp 337-346. https://doi.org/10.1038/nature06599

Shao F, Dong L, Dong H, Zhang Q, Zhao M, Yu L, Chen Y (2017) Graphene oxide modified polyamide reverse osmosis membranes with enhanced chlorine resistance. J Membr Sci 525:9-17. https ://doi.org/10.1016/j.memsci.2016.12.001

Som C, Berges M, Chaudhry Q, Dusinska M, Fernandes T, Olsen S, Nowack B (2010) The importance of life cycle concepts for the development of safe nanoproducts. Toxicology 269(2-3):160 169. https://doi.org/10.1016/j.tox.2009.12.012

Song X, Zhou Q, Zhang T, Xu H, Wang ZJJ (2016) Pressure-assisted preparation of graphene oxide quantum dot-incorporated reverse osmosis membranes: antifouling and chlorine resistance potentials. J Mater Chem A 4(43):16896-16905

Torad N, Hu M, Ishihara S, Sukegawa H, Belik A, Imura M, Yamauchi Y (2014) Direct synthesis of MOF-derived nanoporous carbon with magnetic Co nanoparticles toward efficient water treatment. Small 10(10):2096-2107. https://doi.org/10.1002/smll.201302910

Ulbricht M (2006) Advanced functional polymer membranes. Polymer 47(7):2217-2262. https://doi.org/10.1016/j.polymer.2006.01.084

Van der Bruggen B, Vandecasteele C, Van Gestel T, Doyen W, Leysen $\mathrm{R}$ (2003) A review of pressure-driven membrane processes in wastewater treatment and drinking water production. Environ Prog 22(1):46-56. https://doi.org/10.1002/ep.670220116

Vilar G, Fernández-Rosas E, Puntes V, Jamier V, Aubouy L, VázquezCampos S (2013) Monitoring migration and transformation of nanomaterials in polymeric composites during accelerated aging. In: Paper presented at the journal of physics: conference series

Wan H, Briot N, Saad A, Ormsbee L, Bhattacharyya D (2017) Pore functionalized PVDF membranes with in situ synthesized metal nanoparticles: material characterization, and toxic organic degradation. J Membr Sci 530:147-157. https://doi.org/10.1016/j. memsci.2017.02.021

Wang R, Hashimoto K, Fujishima A, Chikuni M, Kojima E, Kitamura A, Watanabe T (1997) Light-induced amphiphilic surfaces. Nature 388(6641):431. https://doi.org/10.1038/41233

Wang G, Qian F, Saltikov C, Jiao Y, Li Y (2011) Microbial reduction of graphene oxide by Shewanella. Nano Res 4(6):563-570. https ://doi.org/10.1007/s12274-011-0112-2 
Wang N, Ji S, Zhang G, Li J, Wang L (2012a) Self-assembly of graphene oxide and polyelectrolyte complex nanohybrid membranes for nanofiltration and pervaporation. Chem Eng J 213:318-329. https://doi.org/10.1016/j.cej.2012.09.080

Wang Z, Yu H, Xia J, Zhang F, Li F, Xia Y, Li Y (2012b) Novel GOblended PVDF ultrafiltration membranes. Desalination 299:50 54. https://doi.org/10.1016/j.desal.2012.05.015

Wang J, Zhang P, Liang B, Liu Y, Xu T, Wang L, Pan K (2016) Graphene oxide as an effective barrier on a porous nanofibrous membrane for water treatment. ACS Appl Mater Interfaces 8(9):62116218. https://doi.org/10.1021/acsami.5b12723

World Health Organization (2018) Drinking-water. https://www.who. int/news-room/fact-sheets/detail/drinking-water. Accessed $16 \mathrm{Feb}$ 2019

Wu J, Yu C, Li Q (2015) Regenerable antimicrobial activity in polyamide thin film nanocomposite membranes. J Membr Sci 476:119127. https://doi.org/10.1016/j.memsci.2014.11.030

Xu Z, Zhang J, Shan M, Li Y, Li B, Niu J, Qian X (2014) Organosilane-functionalized graphene oxide for enhanced antifouling and mechanical properties of polyvinylidene fluoride ultrafiltration membranes. J Membr Sci 458:1-13. https://doi.org/10.1016/j. memsci.2014.01.050

Yang Q, Lin X, Su B (2016) Molecular filtration by ultrathin and highly porous silica nanochannel membranes: permeability and selectivity. Anal Chem 88(20):10252-10258. https://doi.org/10.1021/acs. analchem.6b02968

Yin J, Deng B (2015) Polymer-matrix nanocomposite membranes for water treatment. J Membr Sci 479:256-275. https://doi. org/10.1016/j.memsci.2014.11.019

Yu L, Zhang Y, Zhang B, Liu J, Zhang H, Song C (2013) Preparation and characterization of HPEI-GO/PES ultrafiltration membrane with antifouling and antibacterial properties. J Membr Sci 447:452-462. https://doi.org/10.1016/j.memsci.2013.07.042

Zaman N, Rohani R, Mohammad A, Isloor A (2018) Polyimidegraphene oxide nanofiltration membrane: characterizations and application in enhanced high concentration salt removal. Chem Eng Sci 177:218-233. https://doi.org/10.1016/j.ces.2017.11.034

Zhang C, Ren L, Wang X, Liu T (2010) Graphene oxide-assisted dispersion of pristine multiwalled carbon nanotubes in aqueous media. J Phys Chem C 114(26):11435-11440. https://doi. org/10.1021/jp103745g

Zhang L, Shi G, Qiu S, Cheng L, Chen H (2011) Preparation of highflux thin film nanocomposite reverse osmosis membranes by incorporating functionalized multi-walled carbon nanotubes. Desalination Water Treat 34(1-3):19-24. https://doi.org/10.5004/ dwt.2011.2801

Zhang Z, An Q, Liu T, Zhou Y, Qian J, Gao C (2012) Fabrication and characterization of novel $\mathrm{SiO} 2-\mathrm{PAMPS} / \mathrm{PSF}$ hybrid ultrafiltration membrane with high water flux. Desalination 297:59-71. https:// doi.org/10.1016/j.desal.2012.04.017

Zhang J, Xu Z, Shan M, Zhou B, Li Y, Li B, Qian X (2013) Synergetic effects of oxidized carbon nanotubes and graphene oxide on fouling control and anti-fouling mechanism of polyvinylidene fluoride ultrafiltration membranes. J Membr Sci 448:81-92. https://doi. org/10.1016/j.memsci.2013.07.064

Zhang R, Liu Y, He M, Su Y, Zhao X, Elimelech M, Jiang Z (2016) Antifouling membranes for sustainable water purification: strategies and mechanisms. Chem Soc Rev 45(21):5888-5924. https:// doi.org/10.1039/c5cs00579e

Zhao X, Ma J, Wang Z, Wen G, Jiang J, Shi F, Sheng L (2012) Hyperbranched-polymer functionalized multi-walled carbon nanotubes for poly (vinylidene fluoride) membranes: from dispersion to blended fouling-control membrane. Desalination 303:29-38. https ://doi.org/10.1016/j.desal.2012.07.009

Zhao Y, Xu Z, Shan M, Min C, Zhou B, Li Y, Qian X (2013) Effect of graphite oxide and multi-walled carbon nanotubes on the microstructure and performance of PVDF membranes. Sep Purif Technol 103:78-83. https://doi.org/10.1016/j.seppur.2012.10.012

Zhao H, Qiu S, Wu L, Zhang L, Chen H, Gao C (2014) Improving the performance of polyamide reverse osmosis membrane by incorporation of modified multi-walled carbon nanotubes. J Membr Sci 450:249-256. https://doi.org/10.1016/j.memsci.2013.09.014

Zodrow K, Brunet L, Mahendra S, Li D, Zhang A, Li Q, Alvarez P (2009) Polysulfone ultrafiltration membranes impregnated with silver nanoparticles show improved biofouling resistance and virus removal. Water Res 43(3):715-723. https://doi. org/10.1016/j.watres.2008.11.014

Publisher's Note Springer Nature remains neutral with regard to jurisdictional claims in published maps and institutional affiliations. 